\title{
GCU
}

Glasgow Caledonian

University

University for the Common Good

\section{Assessing the effectiveness of a capacity building intervention in empowering hard to reach communities}

Steiner, Artur

Published in:

Journal of Community Practice

DOI:

10.1080/10705422.2016.1201561

Publication date:

2016

Document Version

Author accepted manuscript

Link to publication in ResearchOnline

Citation for published version (Harvard):

Steiner, A 2016, 'Assessing the effectiveness of a capacity building intervention in empowering hard to reach communities', Journal of Community Practice, vol. 24, no. 3, pp. 235-263.

https://doi.org/10.1080/10705422.2016.1201561

\section{General rights}

Copyright and moral rights for the publications made accessible in the public portal are retained by the authors and/or other copyright owners and it is a condition of accessing publications that users recognise and abide by the legal requirements associated with these rights.

Take down policy

If you believe that this document breaches copyright please view our takedown policy at https://edshare.gcu.ac.uk/id/eprint/5179 for details of how to contact us. 
Assessing the effectiveness of a capacity building intervention in empowering hard to reach communities

\begin{abstract}
This paper focuses on 'hard to reach' communities with weak histories of engagement and it explores whether facilitated community interventions can empower and develop community resilience. Drawing on data from six communities, the paper indicates a need for tailored and context-specific support that matches local needs. Implementation of community projects is not linear and the delivery of interventions in 'hard to reach' communities is associated with the risk of failure. Developing community resilience amongst communities that do not engage requires long-term interventions, on-going input and a collaborative approach to working with communities in order to support equal and harmonised development.
\end{abstract}

\title{
INTRODUCTION
}

Rural areas around the world face a number of economic, social and environmental changes which have an impact on the quality of life of rural citizens (Steiner \& Markantoni, 2014). Some of the transformations are a result of changing demographic patterns, globalisation, communication technologies, new consumer preferences and demands (Skerratt et al., 2012). It is evident that many rural communities are confronted with rural depopulation and ageing population (Hamilton, Colocousis, \& Johansen, 2004, Steinerowski \& Woolvin, 2012), unemployment and underemployment (Pelling, 2003), insufficient access to and quality of services (Farmer, Steinerowski, \& Jack 2012), school closures (Woods, 2006), lack of transport services and affordable housing, higher costs of living and fuel poverty (Skerratt et al., 2012). Combined with the challenging economic climate of recent years and public 
sector spending cuts, these changes might have severe consequences on the sustainability of rural regions.

In order to increase the efficiency of public sector spending, and to enhance self-reliance and sustainability at the community level, the UK and Scottish governments have introduced a number of policies promoting community empowerment focusing on developing the resilience of communities (Conservative Party [CP], 2010; Scottish Government [SG], 2010, 2013). These initiatives are supported by European Union policies and, for example, its Rural Development Programmes.

This article begins by explaining the meaning of 'empowerment' and 'community resilience'. Then, the paper reviews current European policies and approaches of community interventions supporting rural empowerment and resilience, provides background information on the Rural Development Programme, and presents the Capacity for Change (C4C) initiative introduced in the Dumfries and Galloway region of Scotland. The research methods adopted in this study then are described. Subsequently, based on qualitative data, the paper presents findings exploring the advantages and disadvantages of the Capacity for Change programme. Finally, the paper offers a discussion and conclusions, including the key implications for researchers, policymakers and practitioners. These refer to the extent to which the C4C programme contributed to empowerment and developing community resilience. Consequently, the paper contributes to the current discussion about development of empowered and resilient communities, tests a new model of rural community interventions that targets communities which 'do not engage', and helps to develop new approaches potentially influencing future development programmes.

\section{MEANING OF EMPOWERMENT}

'Empowerment' is a multidisciplinary concept (Cattaneo \& Chapman, 2010). In a broad sense, empowerment relates to strengthening principles of inclusiveness, democracy and sustainable 
development (Singh \& Titi, 1995) and to 'a process of transition from a state of powerlessness to a state of relative control' (Sadan, 1997, p.144). Empowerment relates to receiving power to act through the mechanisms of participation of individuals, community networks, organisations, and institutions (Ahmad, Yusof, Abdullah, 2014). In social science and community development work, empowerment relates to 'a united and systematic effort by a group to gain control over and improve their aggregated lives by defining problems, assets, solutions, and the processes by which change can occur' (Reininger, Martin, Ross, Sinicrope, Dinh-Zarr, 2006, p.213). The concept can also be perceived as the capacity of individuals or groups to make choices and to transform those choices into desired actions and outcomes (Herbert-Cheshire \& Higgins, 2004). Positive community enabling, which is the act of making a subject able to do something by creating the necessary condition, plays an important role here (Ahmad et al., 2014). This process of community enabling also links to the processes of decentralisation (Jupp, 2008) by giving greater responsibility to local actors (McEwan, 2003) with a facilitating and enabling role of public authorities (Pieterse, 2001). As such, previous studies report the positive influences of participatory processes on community empowerment (Fraser, Dougill, Mabee, Reed, McAlpine, 2006). However, a number of authors indicate that the concept of empowerment goes beyond participation, presenting empowerment as an enabling and 'motivational' construct that leads to the transformation of power structures through collective action and individual capacity-building (Mohan \& Stokke, 2000; Barker, 2005). As such, empowerment is a process of 'self-mobilisation' in which individuals and communities become 'agents of their own development' (Elliot, 1999). Some scholars have therefore suggested that motivations for empowerment derive from the negative impacts of powerlessness and a lack of ability to cope with physical and social demands (Conger \& Kanungo, 1988). Importantly, empowered individuals tend to be self-governing. Self-governance, however, needs to be frequently supported by experts whose role it is to 'equip' those individual with self-regulatory skills (Rose \& Miller, 1992) so that they become empowered (Herbert-Cheshire, 2000). 
The concept of empowerment has been a central tenet of sustainable community development whereby people generate the ability to act collectively in order to improve selected elements of their community (Boley \& McGehee, 2014; Perkins \& Zimmerman, 1995). Philips and Pittman (2009) suggest that community development consists of capacity building (developing the ability to act), social capital (the ability to act) and community development outcomes (community improvement). Therefore, Zimmerman (1995, p.583) indicates that community development programmes must develop empowering processes 'where people create or are given opportunities to control their own destiny and influence the decisions that affect their lives'. Community development programmes might, therefore, be essential in providing local people with the capacities to respond positively to change and developing community resilience (see previous studies e.g. Hegney et al., 2008; Magis, 2010; Skerratt, 2013; Murray \& Dunn, 1995; Marsden \& Murdoch, 1998; Day, 1998; Ward \& McNicholas, 1998; Ward \& Jones, 1999; Herbert-Cheshire, 2000; Sharp, Agnitsch, Ryan, Flora, 2002).

\section{UNDERSTANDING COMMUNITY RESILIENCE}

'Resilience' is a complex term associated with various disciplines. While used for many years in areas of physics, psychology and environmental sciences, the concept is evolving in the field of community development. Reviewing literature in the theme of resilience, Skerratt (2013) identifies a spectrum of international research stretching from 'reactive bounce-back' approaches through to 'proactive human agency'. For instance, in physics, resilience refers to the ability of material to bend and bounce back rather than break (Skerratt, 2013). Referring to ecological resilience, Folke (2006, p.259) suggests that the term could be understood as the capacity of a system 'to absorb disturbance and re-organise while undergoing change so as to still retain essentially the same function, structure, identity, and feedbacks'. More recently, however, the concept of resilience started being discussed with regard to social aspects of human life. In a community setting, therefore, resilience is seen as 'the existence, development, and 
engagement of community resources by community members to thrive in an environment characterised by change, uncertainty, unpredictability, and surprise' (Magis, 2010, p.402) and that 'resilience, simply, is about the capacity to adapt to change' (p.408). Community resilience, as opposed to resilience in the physical sciences, is not necessarily about maintaining the current characteristics or the ability to 'bounce back' and 'stay the same'. Rather, community resilience often suggests systemic change, adaptation and proactivity in relation to stresses, changes and challenges (Steiner \& Markantoni, 2014). It could, therefore, be argued that the main feature of community resilience is an adaptive capacity represented through a continuous process which enables a community to thrive, despite ongoing changes in a dynamic socio-economic and natural environment (Milman \& Short, 2008).

Some claim that community resilience is an important indicator of social sustainability (Magis, 2010) and that the personal and collective engagement of community members (associated frequently with social capital) is essential in order for a community to thrive. It has also been argued that resilience is about the ability of individuals and communities to learn from past experiences, being open, tolerant and inclusive, having a sense of purpose, being positive about the future, and having efficient leadership (Hegney et al., 2008). Resilience reportedly promotes greater wellbeing (Aked, Marks, Cordon, Thompson, 2010) by creating common objectives and encouraging community members to work together for the 'greater good'. Building community resilience requires, therefore, a community developing its social capital (Putnam, 1995). As such, social community resilience is largely discussed in terms of social behaviour and social interaction, the ability to act and be proactive, and to be able to influence change to enhance quality life (Steiner \& Markantoni, 2014; Skerratt \& Steiner 2013).

In terms of process, resilience is generally conceived at an individual level and, through the mobilisation of social capital, collaboration and community engagement, it leads to resilience at a group and subsequently community level (McManus et al., 2012; Norris, Stevens, Pfefferbaum, Wyche, 
Pfefferbaum, 2008; Wilding, 2011; Hegney et al., 2008). There is recognition that 'resilience is not a fixed quantity within communities in that it can grow or decline over time' and that if it grows, the capacity to intentionally mobilise people and resources to respond to and influence social and economic change is enhanced (McIntosh et al., 2008, p.6). The ability to influence change therefore requires the existence of empowered communities that are capable of addressing their local issues and designing better future.

\section{POLICIES SUPPORTING SUSTAINABLE DEVELOPMENT THROUGH EMPOWERMENT}

Increasingly, the UK and Scottish policies encourage the movement towards community empowerment, capacity-building at a community level and enhanced community resilience (CP, 2010; Cabinet Office [CO], 2010, 2011; SG, 2007, 2010, 2013, 2014). For example, one of the Scottish Government's National Outcomes states: 'We have strong, resilient and supportive communities where people take responsibility for their own action and how they affect others' (SG, 2007, p.46). Policy suggests that community engagement helps to deliver more responsive services and that community empowerment is important in boosting local democratic participation, developing confidence and skills among local people, increasing numbers of local volunteers and satisfaction with quality of life (SG, 2014). Moreover, the Community Empowerment Bill highlights that 'communities are a rich source of talent and creative potential and the process of community empowerment helps to unlock that potential. It stimulates and harnesses the energy of local people to come up with creative and successful solutions to local challenges.' (SG, 2012, p.6). The UK government 'Big Society' agenda sends a similar message claiming that the 'reform agenda will empower communities to come together to address local issues... giving new powers and rights to neighbourhood groups' (CP, 2010, p.5). Herbert-Cheshire and Higgins (2004, p.289) highlight that development policy and practice 'is based increasingly on community-led strategies that seek to manage risk and facilitate change at the local level with minimal direct state intervention' and that 'it is widely assumed that such development strategies enable local people to have a greater say in 
transforming the fortunes of their communities, and are therefore a means of empowerment.' However, these empowerment policies uncritically assume that citizens are capable of addressing their local challenges and building stronger and more resilient communities. Although the policies appear as positive and inspirational, it is not clear how the transition from state dependence to empowered and resilient communities should happen. While a number of case studies of (what could be perceived as) resilient communities are presented in current literature, whether this is happening across all communities is not known. Current policies imply a high level of readiness across communities and that community resilience can simply happen regardless of the social, economic, environmental and historical background of the communities. Policies therefore exclude existing 'hard to reach' communities with no history of engagement which might not be able to facilitate positive changes and, therefore, develop community resilience. Consequently, policies should recognise that sustainable development requires well-tailored interventions supporting a positive transition of those less capable communities.

The following part of the paper refers to a specific European Union (EU) rural development policy that aims to design better strategies for grassroots community development in EU member states. The next section provides brief background information on the EU's Rural Development Programme (RDP) indicating potential challenges associated with implementing the RDP. Then, though a critique of current approaches to RDP implementation, the paper introduces and tests the Capacity for Change initiative in Scotland which addresses some of the challenges of current rural development interventions.

\section{RURAL DEVELOPMENT IN THE EUROPEAN UNION}

Rural development is an important policy area, affecting over $50 \%$ of the population of the EU and approximately $90 \%$ of EU land (Rural Development Policy, 2013). Rural Development Policy (RDP) aims to stimulate the economic, social and environmental development in rural locations. In the period 2007- 
2013 approximately $11 \%$ of the total EU budget was allocated to RDP. In order to ensure a balanced approach to RDP, all European regions divide their rural development funding between four thematic areas that focus on: (i) improving the competitiveness of the farm and forestry sector through support for restructuring, development and innovation; (ii) improving the environment and the countryside through support for land management as well as helping to address challenges associated with climate change; (iii) improving the quality of life in rural areas and encouraging diversification of economies and, finally; (iv) building local capacity for employment and diversification (RDP, 2013). The latter incorporates the 'LEADER' approach which promotes projects designed and executed by local partnerships to address specific local problems. The forth theme focuses on the 'LEADER' and describes one of its community development programmes.

\section{LEADER and its implementation challenges}

The acronym LEADER originates from the French words 'Liaison Entre Actions de Développement de I'Économie Rurale' which means 'Links between the rural economy and development actions'. It is a local development approach that enables local actors to develop an area by using its endogenous development potential. LEADER approach aims to enlist the energy and resources of people and bodies that can contribute to the rural development process by forming partnerships called Local Action Groups (LAG) at a sub-regional level between the public, private and civil sectors. In practical terms, LEADER gives both the development strategy design and funding powers to the local level, which helps to decentralise power and facilitate community empowerment. The basic administrative unit of LEADER is a non-profit LAG which engages local actors in a given territory (LEADER, 2013).

As a programme, LEADER was first introduced as a pilot initiative in 1991-93 and it involved 217 regions supporting disadvantaged rural areas. The programme continued and in 2000-2006, based on the encouraging results, LEADER expanded and it covered all types of rural areas. In the recent programming 
period (2007-2013) it became a mainstream approach to European rural development covering 2,200 rural territories across the 27 Member States (LEADER, 2013). The current LEADER programme aims to strengthen the rural economy by encouraging local people to take action at the local level, rather than imposing bureaucratic action on them. Thus, in spite of being a top-down initiative, LEADER aims to foster bottom-up developments. Currently EU countries spend at least $5 \%$ of their rural development budget on LEADER projects. In Scotland LEADER is a part of the Scotland Rural Development Programme (SRDP) (SG, 2012) and between 2007-2013 it delivered funding of $£ 52 \mathrm{~m}$ to rural areas. Consequently, LEADER has a potential to bring positive changes mitigating some of the social and economic challenges faced by rural communities.

Within the EU common rural development policy, each EU member formulates its national strategy for rural development and then specific programmes are designed and implemented at regional levels (Rural Development Policy, 2013a). In Scotland, LEADER funding is available to communities to generate and develop local project ideas. The implementation of a project is only possible when a community project application is successfully reviewed and match-funding to support the project is found. This process implies that communities are interested and capable of running the highlighted pre-project activities which are essential for communities to receive financial support. Interestingly, the analysis of previously-funded LEADER projects in Dumfries and Galloway indicated that particular communities regularly apply for external grants to run community projects. This leaves other (possibly less capable) communities without the support and opportunities for generating project funding and, therefore, for local development. Hence, strong, proactive, and entrepreneurial communities can use LEADER funding opportunities to become even stronger while weaker communities less capable of generating community project ideas do not access essential support, potentially becoming weaker. This, in fact, works against the LEADER ethos which, as presented above, is about equal and harmonised rural development. 


\section{Capacity for Change}

Capacity for Change (C4C) was developed and led by Dumfries and Galloway's LEADER programme (SG, 2013). The initiative was designed to identify better strategies for sustainable rural development. C4C aimed to address the challenge of potentially widening disparities between 'strong and capable' and 'weak and less-capable' communities. The two year programme (2011-2013) involved LEADER staff working with small, less-resourced rural communities who have not engaged with LEADER or other major funding streams in any significant way. Less-resourced communities were defined in this project as communities which have lost some or the majority of local services over recent years. Communities that do not engage were selected due to increasing concerns that communities with the highest levels of human, economic and physical capital will develop at the expense of others who lack such skills leading to a process of uneven development rather than a harmonised improvement in economic and social well-being.

Based on the approaches and recommendations for community development identified in the international literature, the anticipated process of the C4C implementation was designed and it is presented in Figure 1. 


\section{Figure 1. Anticipated process of the C4C development}

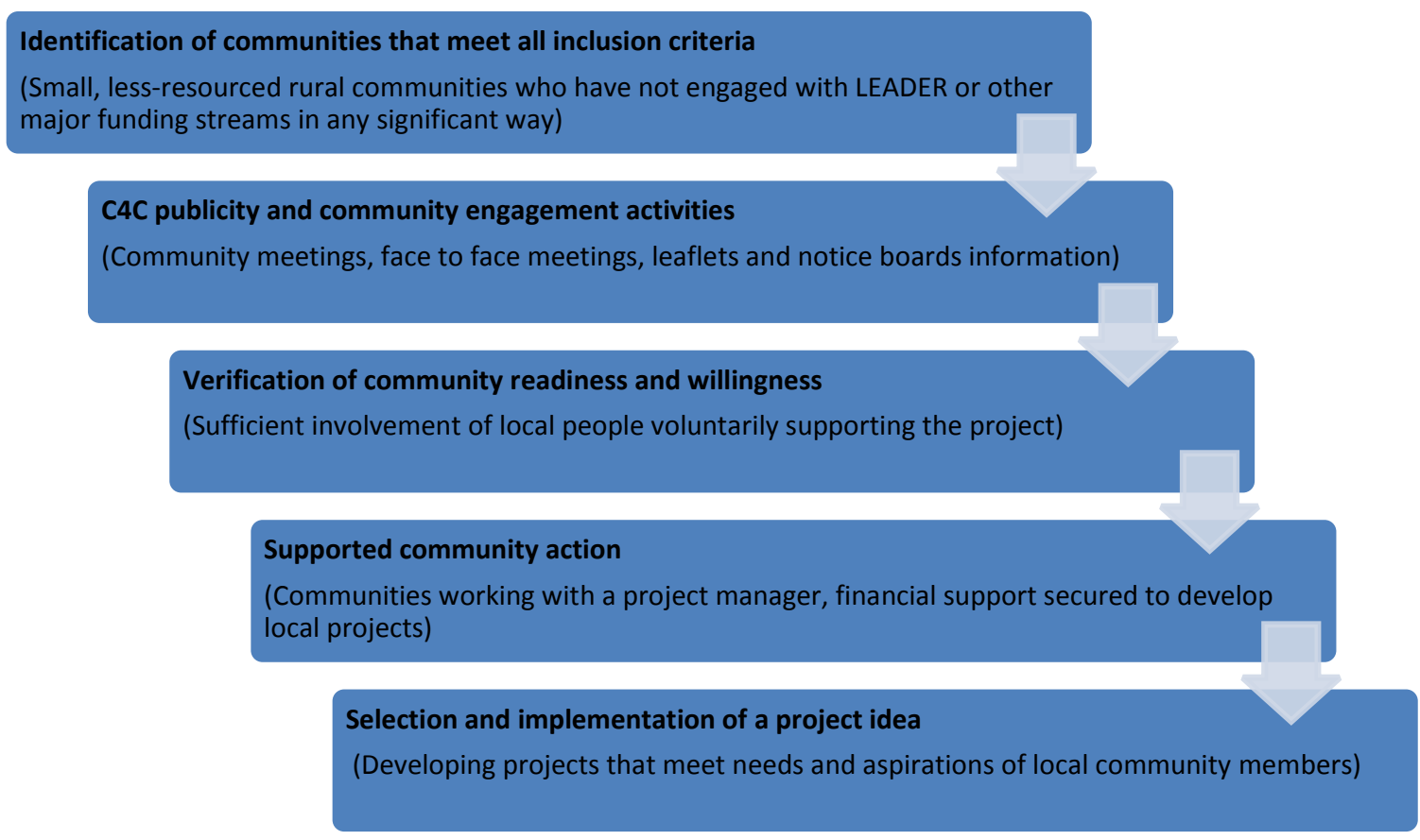

As presented in Figure 1, through direct financial investments and the engagement of the LEADER project manager, $\mathrm{C} 4 \mathrm{C}$ anticipated developing and enhancing communities existing capacity, and work with communities to identify their preferred direction(s) and approach(es) for community development. As such, C4C differed from other LEADER projects in three major ways: (i) instead of waiting for a community project application and its rigorous review, the financial support was offered to selected communities that usually do not engage; (ii) instead of a requirement of finding match-funding, C4C required a sufficient involvement of local people voluntarily supporting the project; and (iii) the project offered additional LEADER support in the form of a project manager who was responsible for assisting the communities in the development of their selected projects. Costs associated with the work of the project manager were covered by LEADER. In addition, participating communities were offered LEADER funds to cover the cost of the project implementation including construction materials, equipment, tools and labor of experts. Work performed by community members was voluntary. 
Thus, through community engagement and empowerment, $\mathrm{C} 4 \mathrm{C}$ aimed to raise capacity, and increase the resilience of the selected communities. The programme aimed to address some of the challenges associated with the current UK and Scottish policies by testing whether policy expectations and the transfer of responsibilities on communities are realistic. Additionally, C4C has presented a new model of financial initiatives which can lead to developing sustainable and empowered rural communities.

\section{METHODOLOGY}

In relation to the geographical context, the $\mathrm{C} 4 \mathrm{C}$ programme focused on villages located in Dumfries and Galloway which is a mostly rural region in the south-west of Scotland. In total, seven communities were invited to take part in the C4C programme. Six of them decided to participate. Data presented in this paper were collected in the second half of 2013 in all six villages participating in the C4C programme and they represent a component of a larger study (note the study consisted of three stages: Stage 1 - mixedmethod approach and 178 baseline interviews; Stage 2 - 30 in-depth qualitative interviews (findings presented in this paper); Stage 3 - longitudinal mixed-method interview component of the study; for more information see Steiner \& Markantoni, 2014; Skerratt \& Steiner, 2013).

C4C focused on small rural communities of between 170 and 430 inhabitants. The names of the villages are not provided to protect people's anonymity. Findings of this paper derive from the 30 in-depth, face to face, semi-structured interviews with $\mathrm{C} 4 \mathrm{C}$ community members conducted by a single interviewer who was a principal researcher. Face-to-face interviewing was used because it allowed focus on the main topics, whilst allowing for elaboration, which is important for deeper understanding of who, why and how questions (Saunders, Lewis, \& Thornhill, 2003). Semi-structured interviews were selected for a number of reasons. Firstly, this type of interview reveals information and issues which the interviewer may not have expected (Bryman \& Bell, 2007). Moreover, this method 'allows interviewers to probe and the interviewees to give narratives of incidents and experiences ... resulting in a more holistic picture of 
people's understandings than a conventional survey analysis' (Brannen, 2005, p.182). Secondly, interviews are a useful method to explore and examine feelings and attitudes of diverse people with 'each interview varying according to the interests, experiences and views of the interviewees' (Valentine, 2005, p.111). Thirdly, semi-structured interviews enable a large amount of information to be generated covering a variety of topics (Valentine, 2005).

Interviewed C4C community members consisted of those who got involved in facilitating and running the programme right from the beginning of the programme initiation and with those who joined it afterwards at later stages of its development. C4C community respondents were randomly selected from a list of potential interviewees provided by the C4C project manager. In each location, the researcher collected between four and six interviews. This number was seen as sufficient as this component of the study aimed at pursuing depth, rather than breadth, analysis (Bryman \& Bell, 2007). The interviewer held free-flowing discussions, allowing interviewees to expand on topics of interest. As more interviews were undertaken, it was possible to ask for the opinions of interviewees on points that had been made by previous interviewees, although names and locations were not divulged.

Interviews lasted 40-120 minutes and were recorded, with consent, and subsequently they were transcribed. Interviewees were ensured the anonymity in research outputs. Field notes were also collated and observations recorded. All data were coded, categorised and analysed by the principle researcher using the constant comparison method and analytic induction. The constant comparative method involved breaking down the data into discrete 'incidents' (Glaser \& Strauss, 1967) or 'units' (Lincoln \& Guba, 1985) and coding them to categories. Categories arising from this method helped to identify themes significant to the project's focus-of-inquiry and lead to both descriptive and explanatory categories (Lincoln \& Guba, 1985). In this study, emerging categories underwent content changes as units and incidents were compared and categorised, and as understandings of the properties of 
categories and the relationships between categories were developed and refined over the course of the analytical process. As Taylor and Bogdan (1984, p.126) summarise: "in the constant comparative method the researcher simultaneously codes and analyses data in order to develop concepts; by continually comparing specific incidents in the data, the researcher refines these concepts, identifies their properties, explores their relationships to one another, and integrates them into a coherent explanatory model".

As the data were analysed by a single researcher, there are neither inter-interviewer nor inter-coder problems with reliability (Blumberg, Cooper, \& Schindler, 2005). All transcripts were initially read by the principal researcher and samples were also, independently, read by an independent researcher. To increase study objectivity, emerging themes were discussed by the two researchers and consensus reached on an initial coding schedule. This was used as a basis for systematic analysis of transcripts by the principal researcher using N-Vivo qualitative data analysis software programme. The themes presented in the findings were not pre-determinate but emerged from the data when they were analysed.

\section{FINDINGS}

Three out of six participating C4C communities successfully completed their projects developing different project ideas which aimed to bring a positive change in their locations. These included a new community garden with a sea-side viewpoint, a new kitchen facility in a village hall and the enhancement of a heritage trail. 'Success' was defined as completion of a project within the duration of the $\mathrm{C4C}$ funding stream resulting in the production of the selected service or product. From the 'unsuccessful' group, one community did not finalise the project within the allocated time and two communities failed to implement the project due to disputes and internal conflicts, diverse community needs, rules and regulations and tight project deadlines. 
This section presents descriptive findings and emerging patterns from the six communities and they relate to the role of the C4C programme in empowering communities and building their resilience. In order to do that, we focus on capturing advantages and benefits associated with the C4C initiative, and challenges faced by the programme. Presented findings are supported with exemplary quotes from both successful and unsuccessful communities (the former marked as ' $\mathrm{S}$ ' and the latter as ' $\mathrm{U}$ ').

\section{Advantages and benefits associated with the $\mathrm{C} 4 \mathrm{C}$ initiative}

Respondents highlighted a number of advantages and positive changes that were introduced by the C4C project. These included:

\section{Funding source as a platform for community engagement}

The majority of respondents indicated that finance was a significant factor in developing their local projects. A need for investments was highlighted and the opportunity to receive money without matchfunding meant that community members could instantly work together in order to improve selected features of their villages. Thus, C4C concept was appealing to participating communities: 'We got something for nothing didn't we?... think the idea's excellent...the fact that there is finance available' (S). Hence, being able to access funding without the necessity of the prior development of a community project proposal and its competitive assessment helped to generate the interest of local people. Funding, therefore, can create an incentive for bringing people together and a platform for community engagement, participation and, ultimately, community empowerment.

\section{Inclusion in a regional programme as a trigger of community participation}

Interviewees described their places as 'forgotten' and 'unwanted'. The C4C initiative brought hope to the participating villages: 'We often feel that we are neglected. So to be part of this project was great' (U). Consequently, participating communities appreciated being a part of a bigger regional initiative and 
of LEADER interest in their communities. This non-tangible feeling was a rich source of hope for the future and it was important in promoting the C4C concept.

\section{Development of social capital through community involvement}

One of the commonly indicated positive outcomes of C4C was the enhancement of links between different people and groups within the communities: 'it forced people to work together who normally wouldn't, so that was a positive. It led within the village to an opening of communication channels which was also positive' (U). Respondents indicated that although $\mathrm{C} 4 \mathrm{C}$ did not manage to bring entire communities together, the project enabled different groups frequently those who normally would not collaborate with or were antagonistic towards each other to work collaboratively. However, it was indicated that the level of engagement varied amongst community members: 'The 20 or so people really got involved with it. It's a bit like dropping a pebble into a bucket isn't it, and the waves go. We were very involved and there'd be another layer of people saying, oh that's nice and this is good. Then there'd be another layer of people who sort of comment on it when they went past' (S).

Bringing people together occurred at different levels but also in many different ways giving opportunities for developing 'bonding', 'bridging' and 'linking' social capital (this contributes to developing community resilience; for example see Wilding, 2011). In addition to C4C open meetings, more innovative methods of communication were introduced. Respondents referred, for instance, to setting up and utilising online social media in order to involve those who, due to other responsibilities, did not usually engage in community activities. Once implemented, this kind of 'innovative' solution can create a platform for ongoing communication.

\section{Development of new and appreciation of existing resources}


Delivering a tangible outcome in successful communities was seen by the community members as an essential component of the project: 'We've actually got to the end...there is a tangible result now. And it got the village talking... it's an extra facility...and it's kind of a flagship sort of place at the moment' (S). Arguably, despite being only one of many products of community action, the tangible outcomes of community projects represent a physical manifestation of success which can inspire and motivate communities. Interestingly, although only three communities succeeded in finalising the project and producing those tangible outcomes, the remaining communities referred to enhanced appreciation of existing resources.

Respondents indicated that despite the small size of their villages, many community members would have a problem with identifying all community resources. It was indicated that $\mathrm{C} 4 \mathrm{C}$ was useful in raising awareness of existing local assets: 'C4C brought a lot of people together in the village. It made them maybe appreciate what we already had as well...so that was good' (U). As such, C4C helped to facilitate discussions about the importance of existing local resources in relation to community development and wellbeing. Community empowerment processes can focus, therefore, not only on creating new resources but on the appropriate utilisation of available resources.

\section{Confidence as an essential component of building community resilience}

In the successful C4C communities the project helped to build community confidence and a feeling of accomplishment. This helped to boost community spirit and empower communities in their desire to introduce more positive changes: 'Somebody has given us some money to do something that we really want that will be seen in the village for a long time. I think it's good...People will be interested and perhaps that will encourage, just even if it's half a dozen people, to get more involved...so that's a real advantage' $(U)$. Hence, C4C created a momentum which, if maintained, could be further utilised in future projects. It could be argued, therefore, that the process of building community resilience starts 
with a sufficient level of confidence amongst community members. Knowledge, skills and expertise can come at later stages in the community development process.

\section{Willingness to carry on local community initiatives}

Respondents suggested that C4C helped to increase awareness of LEADER and other community funding bodies and referred to plans associated with developing future projects that could improve community life in their villages. Respondents indicated how C4C inspired people to develop new community initiatives: 'now we're looking into ways to raise money separately to try and get a carpet put in the hall to make it nicer so that if we are having people hiring the hall for a café...so from the kitchen it's spawning other ideas to make the hall more useable' (S). According to the interviewees, therefore, in addition to a physical change, C4C can bring a number of additional benefits including willingness to carry on building local community initiatives and a more positive feeling about the villages, their appearance and available facilities. This 'added value' could be associated with the afore-mentioned boost in confidence. We could speculate that an ability to introduce a process of change might be the biggest, or the most significant, change associated with the C4C intervention.

\section{Supported community action and work of a project manager}

Interviewees' general feeling was that communities need a 'guide'. This guidance needs to be somebody who can generate the initial interest, who knows how to run community projects and is familiar with its key development stages, who is aware of potential challenges and how to resolve them: 'Obviously we didn't know what we were doing and we had somebody to guide us. You definitely need somebody that knows how the project works to help you work through it. Because we wouldn't have known which way to go...We weren't left to cope with the project on our own, there was the support there all the time and we were able to talk to people whether there was a meeting or not... we couldn't have just been given the money and then said 'well go ahead with it' (S). Respondents appreciated that a project manager could 
advise community members on a number of issues including: how to access other funding sources, how to design a management plan or what the different option are in terms of a project development. Moreover, the C4C project manager was frequently compared to a 'timekeeper' and a professional figure who helped to liaise and bring community members together and who ensured that the focus of community discussions remained on the project implementation. Interestingly, the majority of respondents indicated that this 'facilitator/expert' should not come from the immediate local environment as this can influence his/her objectivity and, as such, undermine the project.

\section{C4C challenges}

The study identified a number of challenges associated with the implementation and running the C4C project. These included:

\section{Lack of sufficient information about C4C}

Respondents claimed that the $\mathrm{C} 4 \mathrm{C}$ concept was not well explained and that the rules of the project kept changing. Interviewees suggested that initial examples of what C4C could do or achieve would have been useful. Thus, indicating what, when and how would happen, and who would be responsible for different components of the project should have been clarified at the start of the programme: 'it would've been really helpful for me to just have an A4 explanation of what C4C was about, what the aim was and what kind of things would be helpful throughout the project' (S). Moreover, it was suggested that frequently language ('jargon associated with policy') used by C4C was inappropriate and difficult to understand for local community members. Clear rules and guidelines available to all project stakeholders are essential in introducing and implementing community projects. 


\section{Misunderstanding of the C4C concept}

Respondents reported that community members (especially those not involved directly in the project) believed that $\mathrm{C} 4 \mathrm{C}$ could address some statutory-related issues however LEADER eligibility funding rules indicate that this is not possible: 'it's a nice idea, it's a good idea, rural communities like this need help in various ways. But there are more practical things like the cost of fuel, the cost of heating, transport and all these kinds of things. It's street lighting all these everyday things that...should be doing perhaps' (U). Misunderstandings of what a community project can fund may lead to a confusion and hesitance towards the project from potential community participants.

\section{Administration management issues and lack of staff continuity}

A number of respondents claimed that administration and management of the project were not efficient. C4C was criticised for unclear rules and lack of a coherent implementation strategy: 'The change of leadership...poor chain management is the phrase I would use...we were told one thing and then something else and then something else then it seemed to be that they didn't know what they were doing themselves...the idea was good but the management was poor' (U). Moreover, lack of project continuity was noted when the first project manager decided to leave the programme. Some claimed that the project activities stopped for a number of months and that the replacement of the project manager led to delays in project implementation. It was also noted that a new project manager required reassurance of the accuracy of the earlier selected projects: 'They had three different people heading up this project at various times...you need continuity really. You need somebody who's going to be there from the beginning to the end and somebody who has got a handle on all the necessary institutions, regulations and so on' (U). Interviewees were critical of sudden changes occurring during the project. Consequently, contingency planning ensuring the stability and continuity in the project management is needed. 


\section{Insufficient communication}

Interviewees complained about the lack of communication and, on many occasions, lack of response from C4C project managers. Methods of communication were also questioned with some indicating that email communication is not sufficient and often inappropriate when developing community projects: 'The method of communication was definitely flawed, mega, mega...one of the disadvantages was email, the wrong platform for group discussion' (U). Ongoing communication adapted to community needs should, therefore, be agreed at the initial stage implemented during later stages of the project.

\section{Suspicion and scepticism}

Many community members did not understand reasons for $\mathrm{C} 4 \mathrm{C}$ interventions and why their village was selected to benefit from LEADER funding. Offering financial support during the period of public spending cuts was seen as questionable. Consequently, a lot of people were sceptical and suspicious: 'there's a lot of old people in the village and there's a lot of apathy because people think "oh you don't get money for nothing, there must be something behind why they're giving the money'” (U). This group of people was frequently responsible for introducing a feeling of uncertainty and doubt amongst other community members. Clarifying any queries raised by a community and gaining sufficient community buy-in are essential in a smooth introduction of a community project.

\section{Breadth and longevity of community engagement}

Some respondents indicated that the majority of those who got involved in the C4C programme were already involved in community projects. Interviewees suggested that a wider pool should contribute to the development of the $\mathrm{C} 4 \mathrm{C}$ projects: 'You get some saying we could have done this...but they're the ones that are not involved...everybody assumes that everybody else will do things [but] you've only got half a dozen or so people who are involved' (S). Moreover, respondents questioned whether the 
community engagement generated amongst different community groups is long-lasting or if it collapses after the project. It was noticed that $\mathrm{C} 4 \mathrm{C}$ helped to increase the engagement of some community members but, as the same time, interviewees suggested that more projects like C4C are needed to develop strong links and 'real engagement' facilitating community development projects.

\section{Diverse community needs}

It was noted that different community members have different needs and vision 'There's lots of ideas and people fall out about what is the best idea for their precious village' (S). It might be difficult, therefore, to select one project that would satisfy the whole community. Selecting one project idea and disregarding another one can lead to a conflict and/or disappointment of some community members: "I think that disappointment that people felt they had got some good ideas and only to be told "no that isn't a good idea" I think upset quite a lot of people' (S). Respondents suggested that consensus on one project idea is rarely possible and a decision on the final project selection should follow clear and earlier agreed rules.

\section{Personal agendas, disputes and internal conflicts}

Interviewees explained that not only did people have different needs and visions for the village but internal conflicts, disputes and personal agendas that are frequently historically rooted in many rural places could be destructive. All these 'conflicts' are complex and difficult to resolve, and make introducing and implementing a community project challenging or even impossible. Some respondents from villages that did not succeed in finalising their C4C project indicated this issue as the major contributor to the project failure: "I began to wonder about certain people and their attitude and what they were really aiming for, and I couldn't figure it out...you don't want to be blaming people but...they acted in a way that was not in the interest of the community...that was when the ill-feeling set in...and it wasn't caused by the project leaders, it wasn't caused by the landscape architect, it wasn't caused by 
landowner, it was caused by residents, who for some reason of their own sabotaged it...they weren't community-minded, they were selfish' (U). Early recognition of potential conflicts and appropriate intervention by a project manager might be required in order to save the future of a project. Project managers might, for example, act as negotiators between different community groups providing impartial advice.

\section{Resistance to change}

C4C aimed to bring a positive change to participating communities. According to some respondents the assumption that a village needs support and change might not be necessary correct: 'There are individuals who don't want change. They're quite happy with the way things are, which is absolutely fine. We've always had it this way, it's always been done that way. They're not mentally ready for change' (S). Hence, there were those claiming that changes are not welcomed thus rejecting the concept of the project from the start. Communities, therefore, have the right not to engage and not to change any aspects of their life.

\section{Timelines and deadlines}

C4C was criticised for introducing strict deadlines. It was emphasised that developing and implementing a community project might be time-consuming. Having more flexible deadlines would enable community members to work under less pressure and successfully deliver projects: 'the time allotted by LEADER shouldn't be so strict, it should be more elastic because you come up against problems as well. Giving a strict time limit like that doesn't work' (U). Interestingly, however, there was also a small number of people suggesting that community projects should be short-term and fixed as this helps to become focused on the project delivery. 


\section{Financial accountability}

A few interviewees suggested that the project financial resources were spent on activities that did not represent a priority (this links with earlier described misunderstanding of the C4C concept and what C4C could do for a community): 'there is the underlying feeling of some of us that here is $£ 20,000$ being spent on something that we don't actually need in a climate of financial constraints' (U). Financial decisions are likely to be criticised and, as such, it is important to ensure democratic financial decisions. Explaining and allowing communities to decide how the money is spent is an important component of the empowering process that enable community members to understand the decision-making process and take responsibility for community resources.

In addition, respondents emphasised that, when possible, local businesses and local people should be used to implement community projects. Utilising external resources was criticised and described as 'money wasting': 'When the initial plans were shown to us and the gravel was described as being coming from Ayrshire my immediate reaction was: why are we spending so much time and distance in fetching gravel when we've got our own quarry just on the other side of the bay here and we can get gravel from there' (S). In order to receive widespread support, local projects should be designed in a way to maximise benefits to local stakeholders.

\section{Continuation of $\mathrm{CHC}$}

Interviewees expressed their concern that $\mathrm{C} 4 \mathrm{C}$ represents a short-lived change that exists only during the project life-span: 'The biggest challenge is probably to keep the momentum going. C4C provided the momentum initially and once that money's been spent it's really important for that momentum to be maintained by the community... if C4C had a way of checking in every six months for a period of a couple of years, that would be quite good for the community's point of view to feel that there was still some contact, even though there might not be money, but still a kind of listening ear' (S). A need for an 
ongoing intervention of community development programmes might be therefore required to ensure community resilience deepens and embeds.

\section{Rules, law and regulations}

Respondents referred to a need to follow established rules and regulations which can slow down the implementation of a project. Factors such as land ownership or planning permission might heavily influence the direction of a project: 'Obviously the land is owned by the estate so you had a third party again; it wasn't council [local government] property. So you had really three, four, five organisations all trying to agree on things and it doesn't always work. Sometimes...the landowner would have the final say on things because it is their land' (U). Although this particular example is UK-context specific, interviewees felt that aspects of pre-existing rules, law and regulations should be investigated and verified by project managers before the project implementation.

\section{Geographical and weather challenges}

Although geographical features and the weather remained out of $\mathrm{C} 4 \mathrm{C}$ control, respondents stressed that geography and weather factors should be carefully considered when planning a project: 'Yeah, getting a meeting was difficult because of snow, so the timing was really bad ...The weather up here is always restrictive and we were always, always fighting against that' (U). Interviewees felt that an appropriate management plan is essential to avoid communication breakdowns. Interruptions in the project implementation and lengthy waits for a response from a project manager caused by weather conditions may decrease the level of community motivation and reduce participation.

\section{Danger of dividing communities}

Respondents from communities that did not succeed in finalising C4C projects indicated that C4C can disempower communities and create 'blame everybody else' environment. There is a danger, therefore, 
that unsuccessful community programmes bring resistance toward future community engagement and weaken the structure of a community: 'One of the big disadvantages now is that the outcome is the total opposite of what C4C wanted, this community is divided now, where before we were all one. It can cause animosity. There are neighbours not talking to neighbours...it caused a bit of competition, it was them versus us, we've never had that before and I don't know why that came about' (U). Interestingly, some interviewees claimed that conflicts are frequently embedded within communities and are just waiting to be exposed. If this is the case, community projects might be the way to reveal internal challenges offering a platform for open discussion. Managing conflict might become a part of the project manager role and, therefore, people supporting community projects should have adequate skills and experience in resolving conflicts.

\section{DISCUSSION}

C4C introduced projects which traditionally would not be provided by public bodies and which targeted the needs and aspirations of C4C community members. C4C anticipated fostering community engagement that would lead to community empowerment and community resilience. Through the analysis of advantages associated the C4C intervention (identified in the above section), Table 1 verifies whether, and if so how, the project managed to meet these objectives. 
Table 1. C4C contribution to community empowerment and resilience

\begin{tabular}{|c|c|c|c|c|c|}
\hline \multicolumn{2}{|l|}{ Cause } & Time & \multicolumn{2}{|r|}{ Effect } & Processes \\
\hline Funding source & \multirow{6}{*}{ 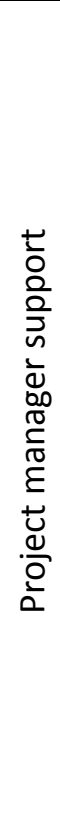 } & & \multirow{6}{*}{ 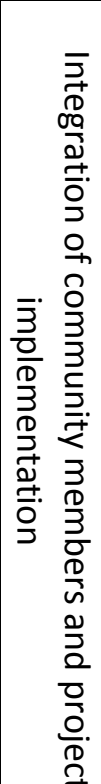 } & $\begin{array}{l}\text { Platform for } \\
\text { community } \\
\text { engagement }\end{array}$ & \multirow{2}{*}{$\begin{array}{l}\text { Incentive to } \\
\text { engage community } \\
\text { members in the } \\
\text { C4C concept }\end{array}$} \\
\hline $\begin{array}{l}\text { Inclusion in a regional } \\
\text { programme }\end{array}$ & & & & $\begin{array}{l}\text { Trigger of community } \\
\text { participation }\end{array}$ & \\
\hline $\begin{array}{l}\text { Community } \\
\text { involvement }\end{array}$ & & & & $\begin{array}{l}\text { Development of social } \\
\text { capital }\end{array}$ & \multirow{2}{*}{$\begin{array}{l}\text { Community } \\
\text { participation in the } \\
\text { project delivery }\end{array}$} \\
\hline $\begin{array}{l}\text { Local needs and } \\
\text { aspirations }\end{array}$ & & & & $\begin{array}{l}\text { Development of new } \\
\text { and appreciation of } \\
\text { existing resources }\end{array}$ & \\
\hline $\begin{array}{l}\text { Successful } \\
\text { completion of a } \\
\text { project }\end{array}$ & & & & $\begin{array}{l}\text { Enhancement of } \\
\text { community confidence }\end{array}$ & \multirow{2}{*}{$\begin{array}{l}\text { Empowerment and } \\
\text { self-belief in ability } \\
\text { to deliver new } \\
\text { projects }\end{array}$} \\
\hline $\begin{array}{l}\text { Willingness to carry } \\
\text { on local community } \\
\text { initiatives }\end{array}$ & & & & $\begin{array}{l}\text { Generation of added } \\
\text { value }\end{array}$ & \\
\hline
\end{tabular}

Table 1 summarises causes and effects of the C4C community development programme. In addition, it highlights processes associated with C4C implementation and the programme's role in engaging communities in community action, enhancing community participation and building community empowerment. As presented, the positive changes associated with the C4C programme were possible due to available funding which incentivised communities to participate in the programme and encouraged people to discuss how to spend available financial resources. The fact that selected communities were invited to take part in a regional initiative created a momentum which was used to engage communities in the project and identify those willing to participate.

C4C was open to all community members and everybody had an opportunity to engage with it. Frequently a number of community members wanted to be involved in discussions about what the project could bring to the village. After this initial process and a decision being made, the engagement of community members in the project was often limited to a few key individuals frequently called 'usual 
suspects', 'community leaders' and those who 'do things for the whole community'. Although those 'individuals' were responsible for project developments, the study found evidence indicating that C4C helped to develop or enhance collaboration between different (often competitive and sometimes antagonistic) community groups which relates to the concept of social capital. The study identified two types of participation in the project including intellectual participation - those who were willing to be involved in decision making, contributing to generating project ideas, sharing thoughts and participating in discussions, and physical participation - those who were willing to deliver 'tangible' tasks and be involved in the implementation of earlier agreed plans.

Engagement as well as intellectual and physical participation led to developing new community resources (e.g. community garden, community hall kitchen, heritage project). The study indicated that communities successful in finalising $\mathrm{C} 4 \mathrm{C}$ projects became more confident and willing to participate in new community projects. This ability to organise and lead new developments relates to the concepts of community empowerment in which community members take an active role in addressing local issues and identifying best local solutions to local challenges.

Importantly, there was consensus that a project manager represented a crucial figure responsible for introducing the project, explaining how C4C operates, supporting ongoing project development, approving community decisions and ensuring that there was ongoing progress. C4C project managers were also seen as a link between a community and (the external support organisation) LEADER. It needs to be emphasised, however, that the majority of positive outcomes presented in this paper are linked with the $\mathrm{C} 4 \mathrm{C}$ communities that managed to successfully complete their projects. Some communities did not complete their developments due to number of challenges (see Table 2). 
Table 2. Challenges of the C4C programme

\begin{tabular}{|l|l|}
\hline \multicolumn{1}{|c|}{ Internal C4C challenges } & \multicolumn{1}{c|}{ External C4C challenges } \\
\hline Lack of sufficient information about C4C & Suspicion and scepticism \\
\hline Misunderstanding of the C4C concept & $\begin{array}{l}\text { Breadth and longevity of community } \\
\text { engagement }\end{array}$ \\
\hline $\begin{array}{l}\text { Administration management issues and } \\
\text { lack of staff continuity }\end{array}$ & Diverse community needs \\
\hline Insufficient communication & Personal agendas, disputes and internal conflicts \\
\hline Timelines and deadlines & Resistance to change \\
\hline Financial accountability & Rules, law and regulations \\
\hline & Geographical and weather challenges \\
\hline & Continuation of C4C \\
\hline \multicolumn{2}{|c|}{ Danger of dividing communities } \\
\hline
\end{tabular}

Identified challenges associated with C4C implementation were divided into 'internal' challenges linked to project design and 'external' challenges that remained out of the control of the C4C team. Understanding and addressing both is essential to improve future community development programmes. If ignored, the factors presented in Table 2 can lead to a failure of local projects dividing and weakening communities.

In relation to internal challenges, the study highlighted the importance of appropriate and coherent design and implementation of community development projects. For instance, $\mathrm{C} 4 \mathrm{C}$ would benefit from clear guidance describing the rules of the programme and showing examples of what could be achieved. Misunderstandings of what a community project can fund may lead to confusion and resistance towards the project. The study shows that stability and continuity in the project management needs to be ensured and communication adapted to community needs. Flexible project deadlines would enable community members to work under less pressure and, if necessary, allow potential challenges associated with the project implementation to be resolved. Restrictive and challenging deadlines might lower community engagement and participation. 
Although external challenges cannot be directly influenced by community development workers and their organisations, it is crucial to be aware of potential factors that can hinder the development of a community programme. Moreover, it is important to find ways to work best alongside external challenges, anticipating certain issues to arise. Our study indicated that clarifying any queries raised by a community and sufficient community buy-in are essential in a smooth introduction of a community project. In relation to 'real' engagement and participation, C4C participants questioned whether a fully democratic approach is feasible and desirable. It was indicated that engaging a wider community might bring a number of challenges. For example, people (or groups of people) might have various ideas and different visions for the village and getting consensus about which project should be implemented is difficult. It would appear, therefore, that when running a project, limited community engagement (or engagement of people with parallel ideas) might be helpful in finalising it. Also, sometimes 'engagement' might not be positive or for 'good reasons'. As such, it is not only the number of people working on a community intervention but their ability to develop and deliver a coherent project. Respondents also highlighted that despite existing opportunities many people simply do not engage in community projects and that engagement is a free choice that belongs to individual community members.

The findings of the study highlight that early recognition of potential conflicts and appropriate actions by a project manager might be required in order to save the future of a project. For example, in some cases a project manager may be able to intervene to save the future of a project at risk by spending time with individuals on both sides of a conflict and then bringing them together. Although these conflicts may have a long history predating the inception of a project, they might hinder implementation of a community programme. Moreover, aspects of pre-existing rules, law and regulations should be investigated and verified by project managers before project implementation. Equally important is consideration of geography and weather before planning a project. Finally, development of empowered 
and resilient communities is a long term process that might require ongoing interventions and community development programmes.

\section{CONCLUSIONS}

The Capacity for Change programme represents a way of addressing some of the challenges associated with current approaches to intensification of 'hard to reach' rural communities that do not engage. Although aiming at sustainable rural development, certain policy assumptions and national and international support programmes might lack a comprehensive approach and, unintentionally, not provide assistance to those most in need. C4C, therefore, complements current LEADER practices and supports policies aiming at developing community empowerment and community resilience.

The presented study showed that programmes like C4C are helpful in engaging rural citizens in community development projects and, when completed successfully, they help to empower communities and contribute to building community resilience. Enabling, which is an important part of the empowering process (Ahmad et al., 2014.), was the core function of C4C offered through financial support and project manager advice. As highlighted by Herbert-Cheshire \& Higgins (2004) community empowerment is expressed through the capacity of individuals or groups to make choices and to transform those choices into desired actions and outcomes. These 'empowerment elements' were evident in the project as: invited communities decided whether or not to participate; community members identified community needs and aspirations and selected one of those as a priority; communities implemented selected project ideas. Moreover, C4C enabled collective action (Mohan \& Stokke, 2000; Barker, 2005) and, in some cases, created positive attitudes and enhanced community motivation towards collaborative community initiatives (Fraser et al., 2006). The study also found evidence of $\mathrm{C} 4 \mathrm{C}$ contributing to the three components of community development identified by Philips and Pittman (2009) including capacity building, social capital and community development outcomes. 
In successful C4C communities, the project helped to build community confidence and inspire people. Bringing people together and opening communication channels amongst different community groups was also, as identified by Wilding (2001), an important factor influencing the development of community resilience. In addition, tangible outcomes brought by the $\mathrm{C} 4 \mathrm{C}$ project are a lasting legacy representing community effort and community empowerment.

Although challenging, working with communities that do not engage seems essential in the successful delivery of programmes which support equal and harmonised rural development. The delivery of community interventions which address those 'hard to reach' communities and people who do not engage is associated with the risk of failure and this needs to be recognised amongst project funders and policymakers. Developing community resilience might require long term interventions and an ongoing input rather than one-off short-term projects. In order to benefit most from C4C-type interventions and increase the success-rate of community development initiatives, project managers should consider internal and external challenges that might be project and place specific.

The findings presented in this paper led to a number of important implications for academics, policymakers and practitioners in relation to community engagement, participation, empowerment and community resilience. Consequently, the article contributes to the existing evidence base and strongly relates to emerging policy directions and the work of community development officers.

For academics, the study highlights that, in the case of communities that do not engage, the process of developing community empowerment and resilience needs to be facilitated by external actors and relevant stakeholders. The ability to respond and influence change, be active and proactive, and find local solutions to local challenges requires skills and some communities need to be enabled to become more resilient. Building confidence amongst community members is a precondition to developing empowered and resilient communities. 
This study suggests that interventions like C4C are one component of the community empowerment jigsaw and, if successfully implemented, they create a favourable environment for developing community resilience. 'Engagement' itself is not sufficient in empowering communities. Rather, what is required is an ability to develop and deliver a coherent project by a unified group of people with appropriate skills and integrated leadership. As such, engagement needs to be followed with adequate participation. Finally, and with regards to C4C, accepting change and an ability to introduce a process of change might be the biggest change itself associated with the C4C intervention. This ability to change and to adapt to new circumstances is a key component of resilient communities.

For practitioners this paper shows that the implementation of community projects is distant from a linear process frequently presented in the literature. The process of project development can be 'bumpy' and associated with many challenges that can lead to a failure. In order to develop successful projects, clear rules and guidelines available to all project stakeholders are essential. Misunderstandings of what a community project can and can not do might lead to confusion and resistance towards the project. The stability and continuity in project management need to be ensured and ongoing communication adapted to community needs introduced. The findings of the study reveal the importance of clarifying any queries raised by a community and sufficient community buy-in in the introduction and the implementation of a community project. In order to do that, local projects should be designed in a way to maximise benefits to local stakeholders and bring a positive multiple effect. Additionally, early recognition of potential conflicts and appropriate interventions upon those might be required in order to save the future of a project. The study also shows that a consensus on one project idea is rarely possible and a fully democratic approach when identifying and selecting a project idea might not be feasible. The study reveals that having more flexible deadlines would enable to work under less pressure and successfully deliver projects. To avoid delays, aspects of pre-existing rules and regulations should be investigated and verified by project managers before project implementation. 
Moreover, geography and weather should be carefully considered when planning the development of a project. It is also crucial to highlight that unsuccessful community programmes can bring resistance toward future community engagement and weaken the structure of a community (hence it can result in the opposite to the desired effect).As such, although C4C targeted specifically rural communities that do not engage, implications for practitioners reinforce the approaches and many recommendations from other community development studies.

For policymakers the study indicated that more projects like $\mathrm{C} 4 \mathrm{C}$ are needed in order to develop strong community links and longevity of community engagement. While being successful in three locations, and despite of the financial support and expertise of LEADER, the C4C intervention failed to deliver in three communities. The high level of community readiness assumed in current policies is, therefore, mistaken. The social, economic, environmental and historical backgrounds of communities influence the extent to which they are capable of embracing current policy suggestions and/or demands. Some communities are strong and capable and others are weaker and more dependent on public support. Hence, community interventions need to be tailored to the needs of particular communities. This applies especially to rural communities who have limited resources and face specific contextual challenges. It is likely that in some locations, long-term interventions supported by external interventions are needed to introduce a gradual cultural shift from being state dependent to being empowered and resilient. Moreover, policymakers need to accept that communities have right not to engage and not to change any aspects of their life. This is because the external perception of what represents a strong or weak community might not be accurate.

\section{ACKNOWLEDGEMENTS}

This research was undertaken as part of the Scottish Government's Strategic Research Programme 'Governance and decision-making for community empowerment' 2011-2016. The author would like to 
thank the LEADER team managing the C4C project and C4C interviewees. Special thanks to Ellie Brodie for her invaluable comments, suggestions and support on this paper. I would like to thank the reviewers for their interest in the paper and their valuable comments and suggestions that helped to enhance the paper. Finally, enormous thank to Susan A. Murty, Ph.D. Emerita Associate Professor for taking her time to review and discuss changes on the paper with the author. 


\section{REFERENCES}

Ahmad, P., Yusof, F., \& Abdullah, F. (2014). Local Economic Growth and Community Sustainability, Procedia-Social and Behavioral Sciences, 101, 437-444.

Aked, J., Marks, N., Cordon, C., \& Thompson, S. (2010). Five ways to wellbeing, The New Economics Foundation. Retrieved from: http://neweconomics.org/projects/five-ways-well-being

Barker, A. (2005). Capacity building for sustainability: towards community development in coastal Scotland, Journal of Environmental Management, 75.

Blumberg, B., Cooper, D. \& Schindler, P.S. (2005). Business research methods, McGraw-Hill Education, Berkshire.

Boley, B., \& McGehee, N. (2014). Measuring empowerment: Developing and validating the Resident Empowerment through Tourism Scale (RETS), Tourism Management, 45, 85-94.

Bryman, A. \& Bell, E. (2007). Business Research Methods, Oxford University Press, Oxford.

Cabinet Office. (2010). Building the Big Society, Cabinet Office, UK.

Cabinet Office. (2011). Strategic National Framework on Community Resilience, Cabinet Office, UK.

Cattaneo, L.B., \& Chapman, A.R. (2010). The process of empowerment: a model for use in research and practice, American Psychologist, 65(7), 646-659.

Conger, J.A., \& Kanungo, R.N. (1988). The Empowerment Process: Integrating Theory and Practice, Academy of Management Review, 13(3), 471-482.

Conservative Party. (2010). Big Society, Not Big Government: Building a big Society, Conservatives, London. 
Day, G. (1998). Working with the grain? Towards sustainable rural and community development, Journal of Rural Studies,14(1), 89-105.

Elliott, J.A. (1999). An Introduction to Sustainable Development. London, Routledge.

Farmer, J., Steinerowski, A., \& Jack, S. (2008). Starting social enterprises in remote and rural Scotland: best or worst of circumstances?International Journal of Entrepreneurship and Small Business, 6(3), 450464.

Folke, C. (2006). Resilience: the emergence of a perspective for socialeecological system analyses, Global Environmental Change 16 (3), 253-267.

Fraser, E.D.G., Dougill, A.J., Mabee, W.E., Reed, M., \& McAlpine, P. (2006). Bottom up and top down: Analysis of participatory processes for sustainability indicator identification as a pathway to community empowerment and sustainable environmental management. Journal of Environmental Management, 78, 114-127.

Glaser, B. G., \& Stauss, A. L. (1967). The Discovery of Grounded Theory, Chicago: Aldine.

Hamilton, L. C., Colocousis, C. R., \& Johansen, T. R. (2004). Migration from resource depletion: The case of Faroe Islands, Society and Natural Resources, 17(5), 443-453.

Hegney, D., Ross, H., Baker, P., Rogers-Clark, C., King, C., Buikstra, E., Watson-Luke, A., McLachlan, K., \& Stallard, L. (2008). Building Resilience in Rural Communities. The University of Queensland and University of Southern Queensland.

Herbert-Cheshire, L. (2000). Contemporary strategies for rural community development in Australia: a governmentality perspective, Journal of Rural Studies,16, 203-215. 
Herbert-Cheshire, L., \& Higgins, V. (2004). From risky to responsible: expert knowledge and the governing of community-led rural development, Journal of Rural Studies, 20, 289-302.

Jupp, E. (2008). The feeling of participation: Everyday spaces and urban change, Geoforum, 39, 331-343.

LEADER. (2013). Information about LEADER. Retrieved from:

http://enrd.ec.europa.eu/leader/leader/en/leader-guide en.cfm

Lincoln, Y., \& Guba, E. (1985). Naturalistic Inquiry, Beverly Hills, CA: Sage Publications Inc.

Magis, K. (2010). Community resilience: an indicator of social sustainability, Society and Natural Resources, 33(5), 401-416.

Marsden, T., \& Murdoch, J. (1998). Editorial: the shifting nature of rural governance and community participation, Journal of Rural Studies, 14(1), 1-4.

McEwan, C. (2003). Bringing government to the people: women, local governance and community participation in South Africa, Geoforum,34, 469-481.

McIntosh, A., Stayner, R., Carrington, K., Rolley, F., Scott, J., Sorensen, T. (2008). Resilience in Rural Communities: Literature Review. University of New England, Australia.

McManus, P., Walmsley, J., Argent, N., Baum, S., Bourke, L., Martin, J., Pritchard, B., \& Sorensen, T. (2012). Rural Community and Rural Resilience: what is important to farmers in keeping their country towns alive? Journal of Rural Studies, 28, 20-29.

Milman, A. \& Short, A. (2008). Incorporating resilience into sustainability indicators: An example for the urban water sector, Global Environmental Change, 18(1),758-767. 
Mohan, G., \& Stokke, K. (2000). Participatory development and empowerment: the dangers of localism, Third World Quarterly, 21(2), 247-268.

Murray, M., \& Dunn, L. (1995). Capacity building for rural development in the United States, Journal of Rural Studies, 11(1), 89-97.

Norris, F.H., Stevens, S.P., Pfefferbaum, B., Wyche, K.F., \& Pfefferbaum, R.L. (2008). Community resilience as a metaphor, theory, set of capacities, and strategy for disaster readiness. American Journal of Community Psychology, 41, 127-150.

Pelling, M. (2003) The Vulnerability of Cities: Natural Disasters and Social Resilience, London: Earthscan, UK.

Perkins, D., \& Zimmerman, M.A. (1995). Empowerment theory, research, and application, American Journal of Community Psychology, 23, 569.

Philips, R., \& Pittman, R.H. (2009). An introduction to community development, New York, Taylor and Francis Ltd.

Pieterse, J.N. (2001). Participatory democratization reconceived, Futures 33, 407-422.

Putnam, R.D. (1995). Bowling alone: America's declining social capital, Journal of Democracy, 6, 65-78.

Reininger, B., Martin, D.W., Ross, M., Sinicrope, P.S., \& Dinh-Zarr, T. (2006). Advancing the theory and measurement of collective empowerment: A qualitative study, International Quarterly of Community Health Education, 25, 211-239.

Rose, N., \& Miller, P. (1992). Political power beyond the state: problematics of government, British Journal of Sociology, 42(2), 173-205. 
Rural Development Policy. (2013). Second pillar of the CAP: Rural Development Policy, fact sheets on the European Union. Retrieved from: http://ec.europa.eu/agriculture/rurdev/index en.htm

Sadan, E. (1997). Empowerment and Community Planning: Theory and Practice of People-Focused Social Solutions. Retrieved from: http://www.mpow.org/

Saunders, M.N.K., Lewis, P., \& Thornhill, A. (2003). Research Methods for Business Students, $3^{\text {rd }}$ ed., Financial Times Prentice Hall, London.

Scottish Government. (2007). The Government Economic Strategy. Retrieved from:

http://www.scotland.gov.uk/Resource/Doc/202993/0054092.pdf

Scottish Government. (2010). Rural Community Empowerment in the $21^{\text {st }}$ Century: Building a 'Can-Do' Culture, Scottish Government, Scotland, UK.

Scottish Government. (2012). A consultation on the proposed Community Empowerment and Renewal Bill, Edinburgh: The Scottish Government, Scotland, UK.

Scottish Government. (2013). LEADER - Links Between Activities Developing the Rural Economy. Retrieved from:http://www.scotland.gov.uk/Topics/farmingrural/SRDP/LEADER

Scottish Government. (2014). Community Engagement and Empowerment. Retrieved from: http://www.scotland.gov.uk/Topics/People/engage

Sharp, J.S., Agnitsch, K., Ryan, V., \& Flora, J. (2002). Social infrastructure and community economic development strategies: The case of self-development and industrial recruitment in rural lowa, Journal of Rural Studies, 18(4), 405-417.

Singh, N., \& Titi, V. (1995). Empowerment for sustainable development: toward operational strategies, London, Zed Books. 
Skerratt, S. (2013). Enhancing the analysis of rural community resilience: Evidence from community land ownership, Journal of Rural Studies, 31, 36-46.

Skerratt, S., \& Steiner, A. (2013). Working with communities-of-place: complexities of empowerment. Local Economy, 28(3), 320-338.

Skerratt, S., Atterton, J., Hal, C., McCracken, D., Renwick, A., Revoredo-Giha, C., Steinerowski, A., Thomson, S., Woolvin, M., Farrington, J., \& Heesen, F. (2012). Rural Scotland in Focus 2012, Edinburgh: Rural Policy Centre, Scottish Agricultural College.

Steiner, A., \& Markantoni, M. (2014). Exploring Community Resilience in Scotland through Capacity for Change. Community Development Journal,49(3), 407-425.

Steinerowski, A., \& Woolvin, M. (2012). Supporting older people in establishing social enterprises in rural Scotland through action research: reflections on challenges and opportunities. Families, relationships and societies, 1(2), 277-286.

Taylor, S. J., \& Bogdan, R. (1984). Introduction to Qualitative Research Methods: The Search for Meanings, New York: Wiley.Wilding, N. (2011). Exploring Community Resilience in Times of Rapid Change, Carnegie UK Trust, Dunfermline.

Ward, K.G., \& Jones, M. (1999). Researching local elites: reflexivity, 'situatedness' and political-temporal contingency, Geoforum, 30, 301-312.

Ward, N., \& McNicholas, K. (1998) Reconfiguring rural development in the UK: Objective 5b and the new rural governance, Journal of Rural Studies, 14, 27-39.

Wilding, N. (2011). Exploring Community Resilience in Times of Rapid Change, Carnegie UK Trust, Dunfermline. 
Woods, M. (2006). Redefining the rural question: The new politics of the rural and social policy, Social Policy and Administration, 40(6), 579-595.

Zimmerman, M.A. (1995). Psychological empowerment: issues and illustrations, American Journal of Community Psychology, 23, 581-599. 